\title{
BUKOWSKI E DROGADIÇÃO: UMA ANÁLISE PARA ALÉM DO 'VELHO SAFADO’
}

\author{
Bruna Moreira Camarotti da Cunha* \\ Lia Carneiro Silveira \\ Francisco Paiva Filho"
}

\begin{abstract}
RESUMO. O abuso de drogas suscita diferentes posicionamentos em variadas culturas e situações no mundo. No plano das políticas públicas, este consumo é abordado como patologia ou como crime. $\mathrm{Na}$ psicanálise, encontramos duas vertentes teóricas: uma considera o gozo do drogado como fora da referência ao sintoma e à fantasia; a outra afirma a necessidade de tomarmos a droga na especificidade da relação que o sujeito estabelece com a castração nas estruturas clínicas. Situando-nos nessa segunda via, objetivamos realizar estudo de caso biográfico de Charles Bukowski, cuja relação com o álcool aparece entremeada com sua produção escrita. Em Bukowski, podemos afirmar que o recurso à droga surge como compromisso (escrever para ir contra o pai) sustentado na fantasia (de espancamento), logo, como sintoma. Verificamos que é possível e necessário pensar a drogadição na neurose, observando no caso a caso como a droga entra na economia libidinal de cada sujeito.
\end{abstract}

Palavras-chave: Psicanálise; drogas; estudo de caso.

\section{BUKOWSKI AND DRUG ADDICTION: AN ANALYSIS BEYOND THE ‘DIRTY OLD MAN’}

ABSTRACT. The use of drugs raises different positions in different cultures and situations in the world. In terms of public policy, this consumption is taken as pathology or as a crime. In psychoanalysis, we find two theoretical strands: one considers the enjoyment of the drugged as out of the reference to the symptom and fantasy, the other affirms the necessity of taking the drug in specificity in the relationship that the subject establishes with castration in clinical structures. Considering this second way, we aim to realize a biographical case study of Charles Bukowski, whose relationship with alcohol appears intertwined with his written work. In Bukowski, we can say that the use of drugs appears as a committed (he wrote to go against his father) based in fantasy (beating) as a symptom. We verified that's possible and necessary to think about drug addiction in neurosis, analyzing case by case as drugs are inserted in the libidinal economy of each subject.

Key words: Psychoanalysis; drugs; case study.

\section{BUKOWSKI Y DROGADICCIÓN: UNA ANÁLISIS MÁS ALLÁ DEL 'VIEJO INDECENTE’}

RESUMEN. El abuso de drogas plantea diferentes posiciones en las diferentes cultura y situaciones en el mundo. En termo de política pública, este consumo se toma como patologia o como un delito. En el psicoanálisis, han dos corrientes teóricas: una se tiene en cuenta el goce del drogadicto como fuera de la referencia al sintoma y la fantasía; la otra afirma la necesidad de tomar la especificidad de la droga en la relación al que el sujeto establece con la castración en las estructuras clínicas. De acuerdo con esta segunda manera, nuestro objetivo es hacer un estudio de caso biográfico de Charles Bukowski, cuya relación con el alcohol aparece intercalada con su obra escrita. Em Bukowski, podemos decir que el uso de drogas aparece como compromiso (escribir para ir en contra de su padre), mantenido en la fantasía (de paliza), así, como un sítoma. Constatamos que es posible y necesario pensar la adicción en las neurosis, señalando en el caso a caso como la droga entra en la economia libidinal de cada sujeto.

Palabras-clave: Psicoanalisis; drogas; estudio de caso.

Enfermeira. Mestranda do Programa de Pós-Graduação Cuidados Clínicos em Enfermagem e Saúde da Universidade Estadual do Ceará. Bolsista Fundação Cearense de Apoio ao Desenvolvimento Científico e Tecnológico - FUNCAP.

\# Psicanalista. Membro da Escola de Psicanálise dos Fóruns do Campo Lacaniano - Brasil. Doutora em Enfermagem pela Universidade Federal do Ceará. Professora Assistente da Universidade Estadual do Ceará..

II Enfermeiro. Mestre em Cuidados Clínicos em Enfermagem e Saúde pela Universidade Estadual do Ceará. 
O abuso de álcool e outras drogas é um fenômeno mundialmente polêmico e complexo que, na atualidade, é caracterizado, na perspectiva da saúde pública, como um problema de saúde mental. Fato é que na sociedade, pautada na incitação ao consumo de algo que proveja prazer, alívio ou cura, existe uma diversidade de paradigmas que norteiam ações perante as drogas, o que repercute na maneira dos sujeitos se relacionarem com a questão: culpabilizando, criminalizando, patologizando os ditos drogados (Souza \& Kantorski, 2007).

No campo da saúde, as ações desenvolvidas são norteadas principalmente por um modelo médico, baseado no conceito de drogadição como doença, apesar de amparadas também por um modelo jurídico que toma a drogadição como crime. Trata-se de um saber que se propõe a tutelar, controlar, vigiar e dirigir a vida daquele que abusa de drogas, considerando que a finalidade principal dessa práxis ainda é a abstinência (Santos \& Costa-Rosa, 2007).

A psicanálise, subvertendo a visão desse modelo, aposta em uma via diferente. Parte do princípio de que o sujeito é divido e, como tal, desejante, ou seja, um sujeito guiado pelo desejo inconsciente. Desse modo, consideramos que a droga não ocupa um lugar equivalente para todo e qualquer sujeito, pois ela se insere na economia libidinal a partir da singularidade das cadeias significantes de cada um (Santos \& CostaRosa, 2007). Aqui a droga, entendida como phármakon, que é compreendida na sua riqueza semântica como droga, remédio, veneno, filtro ou solução (Santiago, 2001). Assim, ao invés de uma solução padronizada a ser aplicada a todo e qualquer sujeito, é preciso identificar o lugar singular da droga, por que esta localização torna-se a condição fundamental para nortear a direção do tratamento (Santos \& Costa-Rosa, 2007).

Ao partir dessas considerações, desenvolvemos este artigo que objetiva compreender como se constroem para o sujeito drogadito suas relações com o objeto droga. Trata-se de uma pesquisa psicanalítica, desenvolvida a partir do método de estudo de caso biográfico. Este método vem na esteira da produção de Sigmund Freud que, de modo paradigmático, instaura um estilo de relatar o caso através de suas constatações biográficas e sintomáticas, como modelos para sua metapsicologia. O método permite ilustrar determinado recorte teórico e, para tanto, pode partir de material clínico, relatos biográficos, entrevistas, dentre outros, pautando-se nos conceitos psicanalíticos para produção de conhecimento (Moreira, 2010).

Neste estudo, tomamos como ponto de partida o material existente sobre a vida e obra do escritor Charles Bukowski. Para isso, consultamos, primordialmente, a biografia intitulada Charles Bukowski - Vida e loucuras de um velho safado (Sounes, 2000); o livro intitulado Misto quente (Bukowski, 1982/2005), de estilo claramente autobiográfico, cujo autor relata a história da infância, da adolescência e do início da vida adulta do seu alterego Henry Chinaski. Além disso, baseamo-nos também na cinebiografia Barfly, de 1987, que teve seu roteiro desenvolvido a partir de uma série de entrevistas com o próprio Bukowski, e no documentário Bukowski: Born Into This (Dullaghan, 2003), que reproduz várias entrevistas realizadas com o escritor.

\section{A PSICANÁLISE E O DITO DO DROGADO}

A psicanálise, nascida do encontro de Sigmund Freud com as histéricas, é uma maneira original de articular a relação entre sujeito e verdade, em que o próprio sintoma se encarrega de falar sobre essa verdade, embora esta última seja totalmente desconhecida no plano da razão consciente. Refere-se à descoberta freudiana do inconsciente, que tem suas próprias leis de funcionamento e comporta o desejo proibido e incestuoso, sobre o qual nem sempre o 'Eu' quer saber.

$\mathrm{O}$ inconsciente, por ser delimitado por um saber não sabido pela consciência, diz respeito a uma outra cena, na qual imperam os componentes pulsionais que insistem em ser satisfeitos, exercendo uma pressão constante e que encontram alguma possibilidade de satisfação, seja na dimensão corporal (sintoma histérico), seja no próprio plano do pensamento (sintoma obsessivo), ou ainda no mundo externo (sintoma fóbico). Ali, a lembrança traumática é apagada, recalcada da consciência, surgindo o sujeito do inconsciente que, a partir de então, somente será acessível à consciência por meio de manifestações, como lapsos de memória, atos falhos, sonhos, chistes e sintomas.

Décadas depois da invenção da psicanálise, o psicanalista francês Jacques Lacan retomou a descoberta de Freud, utilizando-se das lentes da linguística estrutural. Ele atribuiu essa divisão subjetiva ao fato de sermos falantes, ou seja, não há um sujeito desde o início, e sim, é apenas pelo fato de termos que recorrer à linguagem, para endereçar nossas necessidades a um outro, que entramos num caminho que nos permitirá tornamo-nos sujeitos.

Lacan (1957-1958/1999) afirma que, ao nascer, o bebê é um ser da 'pura necessidade' que precisa se dirigir a um outro para sair de seu desamparo inicial, pois não é capaz de se manter vivo se deixado por si mesmo. A mãe (ou aquele que ocupa essa função) é 
quem, inicialmente, vai fornecer não apenas o alimento, mas, principalmente, os significantes com os quais o bebê irá poder se dizer, definindo a fome, sede e as outras experiências por vir. Assim, para Lacan, o inconsciente consiste naquelas palavras que surgem de algum outro lugar que não o da fala do eu, ou seja, o inconsciente é o discurso do Outro (Fink, 1998).

Antes mesmo de nascer, a criança já tem um lugar preparado, preestabelecido no universo simbólico dos pais. Os sujeitos nascem alienados a tudo que lhes precede: aos desejos dos pais, que planejam o nascimento de um filho, nomeiam-no e colocam sobre ele seus ideais. A espera que algo do campo do outro possa nomear seu ser, o sujeito permanece alienado. "O sujeito da alienação supõe que o Outro detém um saber sobre seu ser. Tal saber jamais comparecendo integralmente, o sujeito toma a seu cargo a falta, preservando intacto o lugar do Outro" (Venturini, 2007, p. 173).

Além disso, o bebê ocupa nesse momento, um lugar de objeto em relação ao desejo da mãe, tomado por ela como equivalente fálico. No primeiro tempo do Édipo, segundo Lacan (1957-1958/1999), tem-se a formação de uma espécie de unidade entre a mãe e o bebê que, se não for rompida, pode deixá-lo na impossibilidade de advir como sujeito. Faz-se necessária, portanto, uma outra operação, a da separação.

No segundo tempo do Édipo, a função do pai vai ser intervir nessa unidade mãe-filho, interditando não somente o investimento incestuoso do filho sobre a mãe (tu não te deitarás com tua mãe), mas, principalmente, impedindo que a mãe mantenha o filho no lugar de seu objeto (tu não reintegrarás o produto do teu ventre). No terceiro tempo do Édipo, finalmente, o pai surge como aquele que detém o falo, portanto, aquele que tem o que a mãe deseja (Lacan, 1957-1958/1999).

Esta intervenção lança o sujeito no plano do desejo, em que o Outro não dispõe de todos os significantes. A mãe, para além de sua função materna, também é mulher e, como tal, não se satisfaz do filho. Também falta algo à mãe, posto que ela deseja, esse algo é o pai quem o detém. "O Outro figura aí como faltoso, como incompleto, como parte interessada no jogo, e não como um árbitro que poderia emitir um julgamento sobre o ser do sujeito de uma distância objetiva, imparcial e isenta" (Venturini, 2007, p. 173).

Lacan (1957-1958/1999) afirma que o mais importante no Édipo será o encontro com a castração e o modo como o sujeito irá se posicionar diante dela. Recalcamento, foraclusão e denegação são as três formas de defesa frente à castração, respectivamente correspondentes à neurose, psicose e perversão. No caso da psicose, tem-se um mecanismo que não conserva registro do encontro traumático. O psicótico 'nada sabe' sobre a castração, pois não ocorreu a inscrição simbólica de um significante que poderia responder por essa falta. Ou seja, o significante é foracluído do simbólico, retornando no real pela alucinação e/ou pelo delírio. Na perversão, o sujeito diz 'eu sei' sobre a castração, mas a recusa, a desmente. Portanto, o perverso renega a lei, representada pelo pai, colocando-se acima dele e elegendo o falo como existente na mãe (Fink, 1998).

Já na neurose, o sujeito 'nada quer saber' sobre a castração. Ao invés de se sujeitar como objeto a esse Outro supostamente completo, o sujeito depara-se com um enigma que é o desejo da mãe e, é nesse espaço vazio que poderá se deparará com uma pergunta sobre seu próprio desejo: que queres? Será nesse espaço que se estabelecerá, a partir do recobrimento de duas faltas (falta no sujeito e falta no Outro), que Lacan irá situar como o lugar do objeto. No entanto, não se trata de um objeto do desejo, substância material qualquer que pudesse satisfazê-lo, respondendo ao seu enigma. Mas, do objeto causa do desejo, (a que Lacan chamou Objeto a), cuja única consistência é aquela do gozo, resto impossível de simbolizar. Do lado do sujeito, o que se tem é a sua divisão, decorrente da extração do objeto. Como sujeito barrado, irá estar para sempre dividido, ignorando seu desejo e aquilo que o causa.

O objeto, tido pelo sujeito como perdido, é que irá demarcar suas relações com a realidade. Como afirma Freud (1950[1895]/1996a), não buscamos por encontrar no mundo um objeto que satisfaça o desejo, mas por reencontrarmos o objeto perdido da experiência de satisfação. No entanto, ele é também objeto incestuoso, interditado, que quando começa a aparecer faz surgir a angústia. A fantasia será a fórmula arranjada pelo sujeito para sustentar uma relação com esse objeto que, ao mesmo tempo em que o presentifica, mantém-no a certa distância.

$\mathrm{O}$ dito drogado não se encontra distante desse contexto. Freud (1929/1996b) elucida que uma das medidas paliativas que o sujeito encontra para lidar com o mal-estar experimentado na vida em civilização é a droga, considerando que o método químico da intoxicação é a medida paliativa mais grosseira, embora a mais eficaz em proporcionar sensações prazerosas que amenizam o mal-estar e a angústia do sujeito.

Portanto, o drogado é aquele que, ao se deparar com a castração simbólica e com o mal-estar gerado pelas exigências e ideais sociais, irá recorrer à droga como um modo específico de gozo. Seja para instaurar uma barra que impeça a invasão do Outro (na psicose), seja para escapar da falta da castração (na neurose) ou ainda para denegá-la (na perversão). 
Atualmente, verificamos diferentes posições teóricas, na psicanálise, acerca da relação do sujeito com o objeto droga. Lisita e Rosa (2011) apreenderam que há uma vertente teórica psicanalítica que considera o gozo do drogado como estando fora da referência ao sintoma e à fantasia, uma vez que, ao romper o casamento com o gozo fálico, o sujeito faria um curto circuito com a droga. Assim, a relação do uso que os sujeitos fazem de determinadas substâncias químicas concerne, exclusivamente à questão do gozo sem relação com as formações do inconsciente, fora do campo das neuroses.

Por outro lado, há a corrente que considera a necessidade de se tomar a droga na especificidade da relação que o sujeito estabelece com a castração, privilegiando assim a subjetividade e a singularidade de cada caso. Assim, "cabe investigar as circunstâncias em que esse uso acontece e seus efeitos e, com base nisso, buscar elementos capazes de auxiliar na definição do diagnóstico estrutural, fato fundamental para a condução do tratamento" (Lisita \& Rosa, 2011, p. 274).

Este estudo situa-se nessa segunda via de pensamento e serve-se da análise do caso Bukowski para ilustrar como, no neurótico, a droga pode estar a serviço da fantasia, permitindo a manutenção de uma certa relação do sujeito com o objeto $\mathrm{S} \diamond \mathrm{a}$.

\section{CHARLES BUKOWSKI - PARA ALÉM DO VELHO SAFADO}

Iniciamos a apresentação do caso com um dos poemas de Bukowski intitulado "Como ser um grande escritor", que sintetiza de forma crua e poética como ocorre para ele a relação com o álcool e o papel desse na sua produção escrita:

Você tem que trepar com um grande número de mulheres Belas mulheres/ E escrever uns poucos e decentes poemas de amor./ E não se preocupe com a idade e/ou com os talentos frescos e recém-chegados./ apenas beba mais cerveja mais e mais cerveja..../ e não se esqueça do Brahms e do Bach e também da sua cerveja./não exagere no exercício/.... E se você tem a capacidade de amar Ame primeiro a si mesmo. /.... fique com a cerveja./ a cerveja é o sangue contínuo./ uma amante contínua./ arranje uma grande máquina de escrever e assim como os passos que sobem e descem/ do lado de fora de sua janela/ bata na máquina bata forte/ faça disso um combate de pesos pesados/ faça como o touro no momento do primeiro ataque/ e lembre dos velhos cães que brigavam tão bem: Hemingway, Céline, Dostoievski, Hamsun./ se você pensa que eles não ficaram loucos em quartos apertados assim como este em que agora você está/ sem mulheres sem comida sem esperança/ então você não está pronto./ beba mais cerveja. Há tempo. E se não há está tudo certo também. (Bukowski, 2010, p. 91).

A receita que Bukowski apresenta no poema envolve temas considerados tabus, como o sexo, a morte, a violência extrema. Em meio a tudo isso, como que para permitir e mediar essa aproximação, o álcool, a cerveja, o sangue contínuo. Na elaboração deste estudo, mereceu nossa atenção a relação que o ato da escrita mantém com o consumo do álcool para Bukowski. Enquanto para a maioria das pessoas parece pouco provável que alguém sob forte efeito do álcool possa conduzir tarefas cotidianas, como cuidar da casa ou fazer compras, para ele era, na verdade, seu recurso usual para conseguir produzir algo. Como ele mesmo afirmou em entrevista conduzida por Sean Penn, na Interview magazine, em setembro de 1987:

O álcool é provavelmente uma das melhores coisas para chegar em cima da terra - ao lado de mim. Sim ... estes são dois dos maiores chegadas sobre a superfície da terra. Então ... nos damos bem. Afinal, é destrutivo para a maioria das pessoas. Eu sou apenas um, fora isso. Eu faço tudo do meu trabalho criativo quando estou intoxicado. (...) Então eu gosto ... sim. (Bukowski, 1987).

É curioso imaginarmos como Bukowski seria abordado pelas políticas públicas se vivesse na atualidade. Com ações que tem como foco a abstinência, provavelmente, a tentativa seria de afastálo deste hábito, considerado destrutivo, e 'curá-lo' de sua doença. No entanto, quando escutamos a fala que perpassa pela sua escrita, o que se destacam é o álcool e sua consequente desinibição para escrever que é, na verdade, sua tentativa de cura, como escrito em um dos seus desenhos: "Essas palavras que escrevo me protegem da completa loucura" (Sounes, 2000, p. 254). Como é possível, então, pensarmos a relação desse intenso escritor com o álcool sem cair em um viés curativo e moralizante? Dito em outras palavras, ao invés de assumirmos Bukowski como um doente a ser curado, como permiti-lo ensinar um pouco mais sobre o lugar que a droga pode ocupar na economia libidinal de uma pessoa?

Neste estudo, pretendemos exatamente seguir por essa via. Não se trata de interpretar a obra do escritor através de sua vida, nem de tentar 'psicanalizar' o autor e seus personagens. Mas, sair do lugar do especialista, aquele que sabe sobre as drogas, para aprender um pouco mais com esse grande escritor. 
O primeiro aspecto que merece nossa atenção na relação de Bukowski com a bebida é o caráter destrutivo desse encontro. Além de beber intensamente, suas noitadas frequentemente acabavam em alguma briga séria. Extremamente embriagado, dirigia insultos e provocações e, praticamente, colocava-se em situação de ser surrado em brigas de bar. A agressividade também é frequente nas relações com as mulheres. Aquelas com quem se envolvia, eram depois acusadas de promíscuas, por traí-lo, enganá-lo. Mas, como o próprio Bukowski aponta no documentário, é o sangue de seu pai que fala nessas situações: [Meu pai] "era tão estúpido quanto covarde e seu sangue era meu sangue.... às vezes eu sinto o sangue do meu pai correndo em mim. A merda do sangue de galinha que eu tenho em mim. É uma sensação ruim" (Dullaghan, 2003).

Um pai rude, covarde, capaz das maiores vilezas. É assim que se apresenta a corrente paterna no discurso de Bukowski: "Ele sempre estava zangado com alguma coisa... [e] não me era permitido brincar com outras crianças" (Bukowski, 1982 /2005, p. 13).

Certo dia, após uma briga de colégio, Henry Jr. (como Bukowski era chamado pela família) chega a casa com uma carta do diretor endereçada a seus pais. Este foi o início de uma série de surras que passaram a ocorrer com maior frequência, marcando de maneira indelével sua infância e relação com o pai. Mais que isso, podemos perceber como a posição que ele ocuparia diante da vida seria exatamente essa que ocupa diante desse pai cruel e violento. $\mathrm{O}$ poema ${ }^{1}$ intitulado 'Meu Pai', escrito por Bukowski, é singularmente exemplificador dessa posição.

Uma das tarefas que Bukowski recebia do pai era a de aparar a grama do jardim, seguida da observação de que não deveria deixar "nenhum fiapinho de grama sobrando" (Bukowski, 1982/2005, p. 39). No entanto, recorda que mesmo sabendo que uma surra era certa, sempre esquecia um fiapo: "Sabia que isso ia irritá-lo" (Bukowski, 1982/2005, p. 39). Após as surras, o pai agia como se nada tivesse acontecido. $\mathrm{O}$ pequeno Henry Jr pensava: "essas pessoas não são meus pais, devem ter me adotado e agora não estão satisfeitos com o que me tornei" (Bukowski, 1982/2005, p. 22).

A mãe, uma mulher alemã que trabalhava como doméstica, aparece no discurso de Bukowski como alguém extremamente submissa e que nunca impedia o pai de ir aos seus extremos quando o espancava. Referia-se ao marido como 'paizinho' e, quando Henry Jr. reclamava por ela não defendê-lo, respondia: "O pai está sempre certo" (Bukowski, 1982/2005, p.

1 Poema: Meu pai. Recuperado em 15 de novembro, 2011, de http://velhobukowski.blogspot.com.br/2012/02/poemameu-pai.html. Tradução: Alice Dias.
22). Ainda pequeno, descobre que o pai traía a mãe. "Senti que meu pai estava fazendo minha mãe muito infeliz... Vou matar você - eu disse a meu pai. Ele veio em minha direção e me deu um tapa no ouvido, me derrubando no chão" (Bukowski, 1982/2005, p. 29).

Outra descoberta que marcou a infância de Bukowski foi que seus pais faziam 'aquilo', pronome com o qual designava a relação sexual.

Era difícil para mim acreditar. Minha mãe tinha um buraco e meu pai tinha um pinto que espirrava suco. Como eles podiam ter coisas como essas e continuar caminhando como se tudo fosse normal?... Sentia realmente vontade de vomitar quando encarava a idéia de ter começado a partir do suco do meu pai... Que coisa terrível! (Bukowski, 1982/2005, p. 30).

Bukowski define a sua infância como uma história de horror. No documentário, ele refere-se à casa da infância como "a casa dos horrores, a casa da agonia, a casa em que eu quase me matei... Eu cresci a base de surras de cinta. Três vezes por semana, dos seis aos onze anos. Sabe quantas surras são essas?" (Dullaghan, 2003).

O álcool aparece pela primeira vez na sua vida por volta dos 13 anos de idade. Ao experimentar os efeitos do álcool, descobriu que nunca se sentira tão bem na sua vida. "Era melhor do que masturbação... Era mágico. Por que ninguém havia me falado a respeito disso? Com a bebida, a vida era maravilhosa, um homem era perfeito, nada mais poderia feri-lo" (Bukowski, 1982/2005, p. 57).

No início da adolescência, também começou a enfrentar o pai, e foi quando as surras frequentes tiveram fim. Certo dia, mais uma vez, o pai pediu para que ele baixasse as calças e a cueca:

Não fiz o que mandava. Ele se postou na minha frente, desafivelou meu cinto, desabotoou minha calça e a arriou. Baixou minha cueca. A correia desceu. Era o mesmo som explosivo de sempre, a mesma dor. Mas as lágrimas não brotavam. Pensei em matálo... A dor continuava lá, mas o medo que até então eu sentira havia desaparecido. Meu pai pareceu ter notado a diferença em mim e começou a golpear com mais força, vez após vez, e quanto mais ele batia menos eu sentia. Era quase como se ele estivesse na posição de vítima. Alguma coisa acontecera, alguma coisa mudara. Meu pai parou. [Então eu disse] Bata mais um pouco, se isso faz com que você se sinta melhor. Meu pai se virou e saiu. Ele sabia. Foi a última surra que levei. Dele. (Bukowski, 1982/2005, p. 28). 
Ainda na adolescência, Bukowski começou a sofrer com a acne vulgar, um caso muito grave que o deixou com uma aparência asquerosa, segundo ele, "Era o caso mais grave em toda a cidade... Mas eu sabia como era difícil para as pessoas terem que me olhar. Eu tinha vergonha das minhas espinhas" (Bukowski, 1982/2005, p. 77). Foi nesse momento, marcado pela rejeição que sua aparência despertava e pela dificuldade no acesso ao outro sexo, que ele começou a escrever, como afirmou no documentário "Eu escrevi sem parar. Pareceu bem fácil, uma coisa agradável de se fazer e continuou uma coisa fácil e agradável de fazer... Meu pai descobriu meu pequeno relato e rasgou-o em pedaços" (Dullaghan, 2003).

Anos depois, ao constatar o estilo escrachado de seus textos, o pai expulsou Henry Jr. de casa e sua mãe pediu-lhe que não voltasse, pois correria o risco de ser morto por seu pai. Então, aos 20 anos, deixou a casa de seus pais, com uma definição em relação a seu estilo que estava na contramão das expectativas paternas, como pode ser observada no documentário: "Se meus pais começassem a gostar de meu trabalho algo estava ruim" (Dullaghan, 2003). Indo morar sozinho, sem emprego e sem dinheiro, Bukowski passou a procurar uma vida cada vez mais desprovida de conforto, vivendo com pouco dinheiro, aproximando-se daquele que, assim como ele, estavam à margem da sociedade: "O pensamento de ser alguém na vida não apenas me apavorava, mas também me deixava enojado" (Bukowski (1982/2005, p. 119).

Desse modo, vivendo em cortiços das periferias, bebendo e brigando nos bares, construiu sua literatura, de caráter predominantemente autobiográfico, com temas e personagens marginais: prostitutas, sexo, alcoolismo, ressacas e corridas de cavalos, valendo-lhe a alcunha de "Velho Safado".

A saúde de Bukowski passou por diversos abalos, principalmente em decorrência do abuso de álcool. Após alguns pensamentos suicidas, aos 41 anos tentou se suicidar com gás de cozinha. No documentário afirma: "Sou um suicida sem remissão" (Dullaghan, 2003). Isto era perceptível, pois vivia "matando-se de gole em gole" (Sounes, 2000, p. 127), como afirmou a ex-namorada Linda King. Passou por três tratamentos para remoção de câncer de pele, contraiu tuberculose, e, em 1993, foi diagnosticado com leucemia. Após uma internação para realizar quimioterapia, saiu do hospital bebendo e fumando. Em março de 1994, Bukowski morreu de pneumonia, decorrente do tratamento de leucemia, na Califórnia, aos 73 anos de idade (Sounes, 2000).

\section{ANÁLISE DO CASO}

$\mathrm{O}$ ponto de partida de nossa análise refere-se à tentativa de localizar o lugar que o objeto droga ocupava para Charles Bukowski. A suposição de que estamos diante de um sujeito estruturado de forma neurótica parte de três pontos: a forma como ele se situa frente ao Outro da linguagem, sua construção de um romance familiar e sua divisão subjetiva. Quanto ao primeiro ponto, percebemos que sua escrita foi marcada por um uso da linguagem ancorado falicamente, na medida em que afirmava escrever para não ser apreciado pelo pai, ou seja, algo direcionado para o pai, como aquele que porta o falo. $O$ pai surge como aquele que tem o falo e que possibilita a identificação por parte do sujeito - ainda que uma identificação às avessas, como é o caso Bukowski, mas é em relação ao pai que ele define seu lugar no mundo, observado em suas palavras no documentário: "se ele [pai] quer ser rico, eu vou ser pobre; e se ele gostar do que eu escrevo, é porque está ruim" (Dullaghan, 2003).

É essa ordem que, uma vez instituída, possibilitará o deslizamento da linguagem e a produção de metáforas, para além de um sentido fechado. $\mathrm{O}$ psicótico, por não poder recorrer ao Nome-do-pai para organizar cadeias simbólicas, trata as palavras como coisas, num discurso sem metáforas. Além disso, o sujeito permanece impossibilitado de atribuir significação para os significantes (Quinet, 2006).

$\mathrm{Na}$ escrita de Bukowski, o uso frequente de metáforas e de outras figuras de linguagem, como a ironia, mostra que se trata de um sujeito para quem a palavra não está colada à coisa. Em segundo lugar, tanto nas entrevistas concedidas como nos textos de inspiração autobiográfica, encontramos em Bukowski a construção de um claro romance familiar. Freud (1909/1996c) afirmou que essa elaboração é formada pelo neurótico em "um pretexto para começar a criticar os pais; para manter essa atitude crítica, utiliza seu novo conhecimento de que existem outros pais que em certos aspectos são preferíveis aos seus" (p. 243).

Freud aduz ainda que contribuem primordialmente nessa construção o sentimento de estar sendo negligenciado, privado do amor de seus pais. No caso de Bukowski, esse sentimento justificase pelos maus-tratos e pelas inúmeras surras que sofreu. A resposta que se coloca para o pequeno Henry Jr. é exatamente aquela apontada por Freud (1909/1996c), como exemplo: "essas pessoas não podem ser meu pais, eu devo ter sido adotado" (Bukowski, 1982/2005, p. 23). Percebemos ainda com Freud que nesse processo fantasístico, "evidencia-se a influência do sexo, pois o menino tem maiores tendências a sentir impulsos hostis contra o pai do que 
contra a mãe, tendo um desejo bem mais intenso de libertar-se dele do que dela" (Freud, 1909/1996c, p. 219).

Logo, temos a construção daquilo que Freud vai chamar de 'Romance familiar do neurótico' em que, através da imaginação, a criança "entrega-se à tarefa de libertar-se dos pais que desceram em sua estima, e de substituí-los por outros, em geral de uma posição social mais elevada. Nessa conexão ela lançará mão de quaisquer coincidências oportunas de sua experiência real" (Freud, 1909/1996c, p. 220).

A técnica utilizada na elaboração dessas fantasias depende da criatividade de cada sujeito. Como aqui observamos o sujeito dotado de extrema inventividade, constatamos que suas fantasias desembocaram na criação artística que, mais tarde, faria de Bukowski, um artista. No texto "Escritores Criativos e Devaneios", Freud (1908/1996d) apontou para a afinidade entre as criações fantasísticas infantis e o processo criativo do escritor:

O escritor criativo faz o mesmo que a criança que brinca. Cria um mundo de fantasia que ele leva muito a sério, isto é, no qual investe uma grande quantidade de emoção, enquanto mantém uma separação nítida entre o mesmo e a realidade. A linguagem preservou essa relação entre o brincar infantil e a criação poética (p. 135).

Esse ponto permite-nos pensar o lugar que a droga ocupa na economia libidinal de Bukowski. Salientamos em primeiro lugar que para ele o álcool e a escrita estavam em uma relação de codependência (ele bebia e para escrever e somente escrevia quando 'intoxicado') e, juntos, possuíam a função de 'salvá-lo da loucura'. Por outro lado, como afirmado, permaneceu patente em seu discurso o quanto sua literatura era dirigida ao pai, ainda que com o intuito de afrontá-lo.

Sabemos que, para o neurótico, aquilo que o salva, que o impede de defrontar-se cara a cara com o elemento traumático que seria experienciado como loucura, como destruição, é a fantasia. Inicialmente, a criança parte da ideia da ausência da castração na mãe. É o que permite localizá-la como o Outro completo, que pode responder com seus significantes acerca do que é o ser do sujeito. É comum, por exemplo, a criança, como fez Henry Jr., imaginar que seus pais não possuem relação sexual. Que a mãe não deseja o pai, pois a ela nada falta. No entanto, chega o momento em que a criança é confrontada com isso, a descoberta de que seus pais fazem 'aquilo'. Como mostra Bukowski (1982/2005), isso é causa de extrema angústia: "Como eles podiam ter coisas como essas e continuar caminhando como se tudo fosse normal?... Sentia realmente vontade de vomitar quando encarava a ideia de ter começado a partir do suco do meu pai” (p. 30).

O pai aparece como inimigo, aquele que faz a mãe sofrer e, posteriormente, é o próprio Bukowski quem vai ocupar esse lugar, ao ser espancado pelo pai. No texto conhecido como 'Bate-se numa criança', Freud (1919/1996e) traz de maneira magistral como se constrói a fantasia de espancamento que, de maneira inconsciente, determina a maneira de gozar desse sujeito. Nesse texto, percebemos que essa temática fantasística $^{2}$ não é exclusividade de Bukowski. Pelo contrário, é, até, bastante frequente. Freud parte da análise de oito casos atendidos por ele, em que havia relatos de uma cena fantasiada, escrita com a seguinte frase: 'bate-se numa criança'. Chama a atenção de Freud o caráter a-subjetivo da frase. $\mathrm{O}$ sujeito não sabe relatar quem bate, nem quem é essa criança que apanha. Além disso, a confissão dessa fantasia se faz associada a sentimentos de vergonha e de culpa, além de ser investida de uma acentuada satisfação autoerótica, sendo, frequentemente, acompanhada de masturbação.

Consoante Freud (1919/1996e), essa fantasia mostra a fixação de determinado traço perverso (sádico/masoquista) da pulsão sexual que vai tentar encontrar caminho em meio ao desenvolvimento psicossexual. Ao longo da análise desses sujeitos, descobriu que, apesar de se apresentar inicialmente, como essa frase sem sujeito (bate-se numa criança), a fantasia na verdade era composta de três tempos.

No primeiro deles, a frase seria 'meu pai bate numa criança que eu odeio'. A criança que apanha nunca é o próprio sujeito, mas outra. O sujeito que bate é reconhecido como sendo o pai. No segundo tempo, tem-se a frase 'meu pai me bate'. Aquele que bate continua sendo o pai, mas a criança que apanha foi substituída pelo próprio sujeito. Essa fase da construção da fantasia, de acordo com Freud (1919/1996e), tem caráter indubitavelmente masoquista, ou seja, é geradora de prazer sexual. Não se trata, portanto, apenas da uma lembrança da experiência de ter apanhado um dia, mas é uma situação da qual o sujeito extrai uma satisfação. Ela não tem existência real e nem mesmo é consciente. Nem por isso abandona as consequências na economia psíquica do sujeito. Além disso, somente pode ser

2

\footnotetext{
Vale ressaltar que, pelo fato de chamarmos essa situação de "fantasística" não estamos considerando que os relatos de Bukowski sobre as surras que recebeu do pai sejam mentirosos. Pelo contrário, a criação da fantasia se apóia em elementos da realidade experienciada pelo sujeito. No entanto, a forma como ela será construída envolve a elaboração de uma "realidade psíquica" que, segundo Freud, é a única que realmente importa para o sujeito.
} 
construída em análise, a partir dos vestígios significantes trazidos pelo sujeito. A terceira e última fase seria, portanto, aquela que resta acessível à consciência e que os sujeitos atendidos por Freud traziam para a análise 'bate-se numa criança'. Na verdade, ela já era o produto de uma construção realizada para driblar o recalque e permitir o acesso a uma determinada satisfação.

Percebemos, portanto, que o que se encontra em jogo na construção da fantasia é a pulsão. Com a leitura que Lacan realiza da obra freudiana, pode-se conceituar claramente a pulsão, distinguindo-a de um instinto. Para Lacan (1973/2008), a pulsão não é algo natural, é na verdade um artifício produzido pela entrada da linguagem no corpo, uma montagem que não cessa de buscar por se satisfazer. Como força constante, não pode ser assimilada a qualquer função biológica: "ela não tem dia, nem noite, não tem primavera, nem outono; ela não tem subida, nem descida. É uma força constante" (Lacan, 1973/2008, p. 157). Resulta, pois, que não há objeto passível de satisfazer a pulsão, ou melhor, não importa o objeto, sua satisfação vai ser contorná-lo, ou seja, alcançar seu alvo completando seu circuito: "não é pelo alimento que ela se satisfaz, mas pelo prazer da boca" (Lacan, 1973/2008, p. 160).

$\mathrm{Na}$ impossibilidade de se satisfazer completamente, irá restar a pulsão, portanto, buscar alguma satisfação parcial ao sofrer algumas vicissitudes, que, mais ou menos, lhe permitem atingir seu alvo, completando seu circuito. Lacan vai apontar que o fundamental na pulsão é o vai e vem, no qual ela se estrutura, ou seja, seu caráter circular, alternando entre pólos: atormentar, ser atormentado; ver, ser visto.

No caso Bukowski, podemos localizar essa construção a partir de seu discurso. Na sua imaginação, seus pais não praticavam sexo, ou seja, sua mãe não desejava, a ela nada faltava. Pelo pai, ele coloca-se em situação de se deixar espancar. Seus relatos acerca das surras apontam inclusive para uma feminilização da sua posição frente a um ritual quase erótico, em que o pai leva-o para um banheiro, vira-o de costas, manda-o descer as calças e... bate. $\mathrm{Na}$ verdade, mesmo sabendo que iria apanhar, Bukowski reconhece que fazia as coisas de forma a deixar um fiapo de grama fora do lugar, algo que incomodava seu pai, sabendo que aquilo seria o pretexto da surra.

Depois se depara com o período da descoberta sexual, seus pais praticavam sexo (que horror!), sua mãe desejava (logo não era completa, não tinha o falo) e seu desejo era orientado para seu pai (ele a trai e ela sofria por isso). Henry Jr. queixava-se do fato de que a mãe nada fazia frente à violência com que o pai o tratava, pelo contrário, reportar-se ao marido por 'paizinho', apontando para o incestuoso da relação.

Chega o momento da mudança. A descoberta da ausência de um objeto no outro que pudesse aplacar a pulsão, obriga-o a abandonar e a efetuar uma espécie de torção. A única possibilidade de satisfação encontrada seria a transformação da meta pulsional (atividade - passividade) e sua reorientação contra o próprio sujeito. Em um processo de inversão, como o próprio Bukowski (1982/2005) ressaltou, o pai passava momentaneamente a ocupar o lugar daquele que era vítima: "Bata mais um pouco se isso faz com que você se sinta melhor" (p. 74). De tanto se deixar bater, o sujeito localiza sua satisfação em uma espécie de revanche às avessas.

Assim, o curso completa-se quando o ciclo pulsional atinge o ponto de partida, ou seja, a fonte pulsional no corpo, não sem antes contornar o objeto no campo do outro. A pulsão implica, necessariamente, em situar o objeto no campo do outro. $\mathrm{O}$ exato momento em que o circuito se fecha sendo, portanto, correspondente ao lugar do sujeito.

Uma vez construída a fantasia, o sujeito passa, inconscientemente, a repeti-la em todas as suas experiências. Como afirma Quinet (2000), a fantasia é a tela que o neurótico coloca em sua janela, é por onde ele enxerga o mundo. O sujeito fica preso a um certo modo de relação com o outro de onde extrai seu gozo, isto é, seu sofrimento, mas também uma certa parcela de satisfação.

A fantasia de espancamento marcou a posição que Bukowski ocupou na vida. Saiu de casa e começou a se identificar com o lugar do pobre, do marginal. Até seu corpo apresentou as marcas dessa marginalização, pois a acne acometeu-o de forma irremediável, desfigurando-o. Se seu pai queria ser rico, ele pretendia ser pobre, viver uma vida de vagabundo em meio a outros marginalizados como ele. Nem mesmo quando começou a ganhar bem com sua obra isso mudou, pois passou um bom tempo gastando tudo, sem a menor consideração pelo dinheiro.

É bastante característica a frase em que descreveu a surra que mudou sua posição: "foi a última surra que levei. Dele" (Bukowski, 1982/2005, p. 74). Exatamente porque Bukowski deixou de apanhar do pai para apanhar da vida, metafórica ou literalmente nas tantas brigas que entrou. Sua literatura escrachada, pornográfica, crua, provoca o nojo, o asco de quem o lê. É como se dissesse: batam-me!

Mas, isso não ocorre, como na fantasia perversa, com o intuito de dividir e suscitar a angústia do outro. Há um retorno sobre a própria pessoa que coloca a ênfase sobre o sujeito barrado, sustentando o lugar do outro como aquele que bate. Isso é exemplarmente dito no poema intitulado 462-0614: "Não escrevo a 
partir da sabedoria./ Quando o telefone toca /eu também gostaria de ouvir palavras/ que pudessem aliviar um pouco alguma/ dessas coisas./ É por isso que meu nome está na/ lista" (Bukowski, 2010, p. 108).

Nesse poema, cujo título é seu próprio número de telefone, Bukowski queixava-se de ser amado apenas pelo que era com escritor, e não pelo seu ser. Mostranos também como o recurso à escrita, longe de ser uma tentativa de dividir o outro, é, na verdade, uma forma de sustentar o lugar do Outro.

Foi, então, que a droga entrou com o seu papel. Para poder fazer isso, foi preciso que ele saísse da sua condição de menino medroso, apavorado com as calças na mão, e passasse para a posição daquele que batia, jogando na cara da sociedade suas misérias, seu lado mais obscuro. Mas, isso não foi sem a intoxicação do álcool! É como ele diz, 'melhor que a masturbação'. Nas palavras de Freud (1912/1996f), é o 'modelo de casamento feliz' aquele do bebedor com a garrafa de vinho que lhe permite uma relação a mais harmoniosa possível. Temos aqui uma modalidade de relação, cujo sujeito se serve da droga como compromisso (escrever para ir contra o pai), sustentado na fantasia (de espancamento), logo, como um sintoma.

\section{CONSIDERAÇÕES FINAIS}

Com este estudo, buscamos presentificar, através da psicanálise, um outro discurso acerca da drogadição, para além daquele das políticas públicas que toma o drogado como doente ou criminoso. Consideramos que, ao lidarmos com a subjetividade, não nos é permitido seguir uma ciência que foraclui a verdade do sujeito e, no caso, seu saber sobre sua relação com a droga. Como afirmou Bukowski (1987), na entrevista que concedeu a Sean Penn:

Creio que o problema entre psiquiatria e seu paciente é que o psiquiatra atua de acordo com o livro, ainda que o paciente chegue pelo que a vida lhe fez. E mesmo que o livro possa ter certa astúcia, as páginas sempre são as mesmas e cada paciente é diferente. Existem muito mais problemas individuais que páginas.

Permeados pela psicanálise, é necessário trabalharmos com a fala do sujeito ao invés de rotulálo como mais um 'dependente químico', pois isto não nós diz nada sobre o sujeito. Este é estruturado pela linguagem, o que nos permite através de seu discurso identificar como ele se situa frente à castração, logo, em sua modalidade de gozo.
Consideramos que somente com a escuta, sustentada no caso a caso, é que será revelado o lugar de importância, em que o sujeito coloca a droga em sua história de vida. No caso de Bukowski, como nos casos de nossa clínica cotidiana, isto somente será possível quando se compreender que o que norteia o uso de drogas está relacionado com a estrutura clínica que é dada na singularidade de cada sujeito.

\section{REFERÊNCIAS}

Bukowski, C. (1987). [Entrevista com Sean Penn, ator e poeta). Recuperado em 20 outubro, 2011, de http://bukowski.net/poems/int2.php

Bukowski, C. (2005). Misto quente. São Paulo: L\&M Pocket. (Texto original publicado em 1982).

Bukowski, C. (2010). O amor é um cão dos diabos. Porto Alegre: LM\&PM.

Dullaghan, J. (2003). Bukowski: Born into this [Filmevídeo]. J. Dullaghan (Dir.). EUA: Magnolia Pictures. 1 documentário biográfico, $115 \mathrm{~min}$. color. son.

Fink, B. (1998). O sujeito lacaniano: entre a linguagem e o gozo. Rio de Janeiro: Jorge Zahar.

Freud, S. (1996a). Projeto para uma psicologia científica. (Edição Standart Brasileira das Obras Psicológicas Completas de Sigmund Freud, Vol. 1). Rio de Janeiro: Imago. (Texto original publicado em 1950 [1895]).

Freud, S. (1996b). O mal-estar na civilização. (Edição Standart Brasileira das Obras Psicológicas Completas de Sigmund Freud, Vol. 21). Rio de Janeiro: Imago. (Texto original publicado em 1929).

Freud, S. (1996c). Romances familiares. (Edição Standart Brasileira das Obras Psicológicas Completas de Sigmund Freud, Vol. 9). Rio de Janeiro: Imago. (Texto original publicado em 1909).

Freud, S. (1996d). Escritores criativos $e$ devaneios. (Edição Standart Brasileira das Obras Psicológicas Completas de Sigmund Freud, Vol. 9). Rio de Janeiro: Imago. (Texto original publicado em 1908).

Freud, S. (1996e). 'Uma criança é espancada': uma contribuição ao estudo da origem das perversões sexuais. (Edição Standart Brasileira das Obras Psicológicas Completas de Sigmund Freud, Vol. 17). Rio de Janeiro: Imago. (Texto original publicado em 1919).

Freud, S. (1996f). Sobre a tendência universal à depreciação da esfera do amor. (Edição Standart Brasileira das Obras Psicológicas Completas de Sigmund Freud, Vol. 11). Rio de Janeiro: Imago. (Texto original publicado em 1912).

Lacan, J. (1999). O seminário, Livro 5: as formações do inconsciente. Rio de Janeiro: Jorge Zahar. (Texto original publicado em 1957-1958).

Lacan, J. (2008). O seminário, Livro 11 - os quatro conceitos fundamentais da psicanálise. Rio de Janeiro: Jorge Zahar. (Texto original publicado em 1973). 
Lisita, H. G., \& Rosa, M. M. V. (2011). Os usos que o psicótico faz da droga. Psicologia em Revista, 17(2), 261-277.

Moreira, J. O. (2010). Pesquisa em psicanálise na pósgraduação: diferentes possibilidades. In Kyrillos Neto, F., \& Moreira, J. O. (Orgs.), Pesquisa em Psicanálise: transmissão na Universidade (pp. 113-129). Barbacena MG: EdUEMG.

Quinet, A. (2000). A descoberta do inconsciente: do desejo ao sintoma. Rio de Janeiro: Jorge Zahar.

Quinet, A. (2006). Psicose e Laço Social. Rio de Janeiro: Jorge Zahar.

Santiago, J. (2001). A droga do toxicômano: uma parceria cínica na era da ciência. Rio de Janeiro: Jorge Zahar.

Santos, C. E., \& Costa-Rosa, A. (2007). A experiência da toxicomania e da reincidência a partir da fala dos toxicômanos. Estudos de Psicologia I, 24(4), 487-502.
Sounes, H. (2000). Charles Bukowski: vida e loucura de um velho safado. São Paulo: Conrad Editora do Brasil.

Souza, J., \& Kantorski, L. P. (2007). Embasamento político das concepções e práticas referentes às drogas no Brasil. SMAD, Rev. Eletrônica Saúde Mental Álcool Drog. Ed. port. [online], 3(2).

Venturini, S. (2007). O sintoma e os impasses na análise. Psychê, 11(20), 165-182.
Endereço para correspondência:
Bruna Moreira Camarotti da Cunha. Rua Benjamin Carneiro Girão, n 185, apto. 02, Bairro: Montese, CEP 60421-550, Fortaleza-CE, Brasil.E-mail: camarottib@gmail.com. 